\title{
La invención del Enemigo \\ (Las figuras diabólicas en el Valle del Ebro, del siglo IV al XVII)
}

\section{INTRODUCCIÓN}

\section{Los Diablos latinos}

Los primeros diablos que nos ocuparán se encuentran en el primer Himno del Peristephanon de Prudencio:

Mira que a vista aquí de todos se doman los demonios feroces, que, como lobos su presa, devoran entrañas, estrangulan las almas mismas y a los sentidos se mezclan.

Ahí un hombre furioso yérguese lleno ya de su enemigo, baba y espuma arrojando, torciendo los sanguíneos ojos, en la tortura expiando crímenes que no son suyos.

Se oyen - y no hay verdugo- los llorosos ayes; desgarran el cuerpo los azotes, y no se ve el látigo, cadenas invisibles en vilo lo levantan.

Así castiga la virtud de los mártires al ladrón inmundo; lo sujeta, lo tuerce, lo abrasa, lo encadena.

Vejado el ladrón sale de las rendidas médulas.

Suelta inmune su presa, huye con las fauces vacías, devuelve todo salvo, de la uña del pie al cabello, confesando que se abrasa, pues habita en la gehenna. (Versos 97 a 111) ${ }^{1}$

1 He introducido numerosas modificaciones en la traducción del presente texto que proporciona la BAC en su edición de PRUDENCIO, Obras Completas (Madrid, 1981); el texto latino correspondiente, según la misma fuente, es el que sigue:

Cerne quam palam feroces hic domentur daemones, qui lupino capta ritu deuorant praecordia, strangulant mentes et ipsas seque miscent sensibus.

Tunc suo iam plenus hoste sistitur furens homo spumeas efflans saliuas, cruda torquens lumina, expiandus quaestione non suorum criminum. 
Prudencio, que escribe su obra en los últimos años del siglo IV, nos habla de un fenómeno especialmente estable. Casi trece siglos más tarde nos encontramos con la siguiente narración:

Por el mismo año [de 1627] Maria de San Martin Garay, natural de la ciudad de Viana, tenia gran multitud de demonios, y nunca auiã hallado remedio para expelerlos: un tio suyo religioso de San Francisco, que se llamaua Fray Diego de Salinas, conjurola mucho tiempo, y la lleuo a diferentes Santuarios, y nunca tuuo remedio, hasta que vino à Valvanera; donde cantãdole el santo Convento la Letania de nuestra Senora, dio grandes gritos, diziendo: La Virgen me mata, aquella me quema: esta Senora es poderosa para que salga. Y con esto salio, y quedo libre, y sana, dando gracias à la Virgen de Valvanera por tan gran fauor ${ }^{2}$.

El primer relato hace referencia al sepulcro de los santos Emeterio y Celedonio, en Calahorra; el segundo, al santuario de Valvanera. Para llegar de Calahorra a Valvanera el viajero debe remontar el curso del río Ebro y de su afluente el Najerilla, pasando del valle a la alta sierra; unos cien kilómetros, o de dos a cinco días de marcha dentro de la provincia de La Rioja. Esos serán los límites espaciales del presente ensayo, aunque sea, claro está, fácil encontrar fenómenos idénticos fuera de ellos.

Serán también sus límites temporales. No es difícil allegar exorcismos semejantes en nuestro siglo, o casi en nuestros días, en ciertos santuarios gallegos o levantinos. Pero esto exageraría las pretensiones y las obligaciones de este artículo. Más simple y más denso puede ser escrutar la vida del diablo en una región acotada durante un período extenso mas también definido; el que abarcan los dos textos citados, que en sentido amplio podríamos llamar «Edad Media» 3 .

Otra posibilidad a la que renuncio es la de alargar hacia atrás mi estudio. No voy a ocuparme de la demonología antigua, sea grecorromana o

Audias, nec tortor adstat, heiulatus flebiles, scinditur per flagra corpus, nec flagellum cernitur, crescit et suspensus ipse uinculis latentibus.

His modis spurcum latronem martyrum uirtus quatit, haec coercet torquet urit, haec catenas incutit, praedo uexatus relictis se medullis exuit.

Linquit inlaesam rapinam, faucibus siccis fugit, ungue $a b$ imo usque ad capillum salua reddit omnia confitens ardere sese; nam gehennae est incola.

2 Diego de SIlva y PaCheco, Historia de la Imagen Sagrada de Maria Santísima de Valvanera... (Madrid: Imprenta de San Martín, 1665), p. 228. Milagro 119.

3 Esa idea de una Edad Media «larga» está tomada de Jacques LE GoFf, Pour une autre Moyen Age: Temps, Travail et Culture en Occident (Paris: Gallimard, 1977), concretamente de su prefacio. 
bíblica, que el cristianismo hereda. Tampoco de la religión indígena sobre la que el cristianismo se extiende. Sabemos demasiado de la primera y demasiado poco de la segunda.

La fecha más legítima del nacimiento de los demonios es probablemente la del contacto entre ambas religiones. Los demonios son hermanos gemelos de los santos, como pasaré a explicar.

\section{El Santo y el Diablo}

El Peristephanon de Prudencio, del que extrajimos el primer fragmento, es una colección de catorce himnos dedicados a santos mártires. Es un clásico del cristianismo, la primera obra hagiográfica de importancia. En su momento, sin embargo, era un texto con dos vertientes polémicas. Por un lado, era una ardiente proclamación del culto a los santos cuando este culto no era plenamente aceptado por todos los sectores del cristianismo ${ }^{4}$. Por otro lado, y más explícitamente, es un desafío a la «gentilidad» aún vigorosa en torno a núcleos seguros de romanismo y cristianismo como la ciudad de Calahorra: la fuerza de los mártires, que expulsa demonios, es la prueba de la verdad de su fe.

El santo es la vanguardia simbólica del cristianismo; por eso mismo también se sitúa en los límites de éste.

La Vita Sancti Emiliani, del obispo Braulio de Zaragoza, escrita en el siglo VI, es en este sentido una continuación fiel de la obra de Prudencio. Es un texto escueto que, según su autor, debería servir como guión para la predicación el día de la fiesta del santo. Con él, Braulio integra en la historia de la Iglesia la vida de un eremita, San Millán, que, por lo que la propia Vita muestra, había rehusado en vida esa integración.

Lo que San Millán hace durante su larga vida, según Braulio, es sobre todo luchar contra el demonio. En dos ocasiones el demonio agrede directamente al santo. La primera físicamente, saliéndole al camino y luchando con él cuerpo a cuerpo. La segunda, por medio de la difamación, recriminándole que se rodee de - aunque piadosas - mujeres; sólo en el primer caso el demonio se muestra personalmente, porque la vaga alusión a «los demonios» que San Braulio hace en el segundo caso parece más una referencia retórica a las malas lenguas.

4 Sobre el culto primitivo a los santos, ver el clásico estudio de Peter Brown, The Cult of the Saints: Its Rise and function in Latin Christianity (University of Chicago Press, 1982). La instauración del culto a los santos habría sido una victoria del patriciado cristiano sobre los obispos, reacios a ese culto que tendía a la autoglorificación de los linajes laicos. 
Habitualmente el demonio no se muestra en persona, sino por medio de los posesos. San Millán es exorcista. Expulsa el diablo que había entrado en el cuerpo de un diácono, y los cinco que atormentan a un siervo del noble Tuencio. Lo mismo hace con otro siervo, éste del conde Eugenio. Libra también a los nobles Nepociano y Proseria, que «assi como estauan juntos en el matrimonio, también lo estauan con el demonio, y estauan ligados, y se creía que cada uno tenía su demonio». Los relatos son someros: Columba, la hija de Máximo, un Curial, era presa del demonio con gran dolor y temor de sus familiares. La llevan inadvertidamente a presencia de San Millán, y éste expulsa el diablo con sólo hacer la señal de la cruz en la frente de la posesa.

Sólo en un caso el hagiógrafo para en detalles, cuando se trata del diablo ocupante de la casa del senador Honorio de Parpalinas:

La casa de Honorio Senador sufría un demonio maldito y sedicioso, el cual estaua tan apoderado della, que hazía en ella mil torpezas cada día. Y no auía quien pudiesse sufrir semejante morador. Finalmente muchas vezes estando el señor de la casa sentado a la mesa con muchos manjares, ponía el demonio en lugar dellos huessos de animales muertos, y muchas vezes estiércol. $\mathrm{Y}$ muchas vezes quando la gente estaua de noche durmiendo, quitándoles los vestidos a los hombres, y a las mugeres, con gran ruydo los colgaua del techo, como si fueran algunos trapos suzios. Angustiado Honorio, y no sabiendo qué hazerse, se animó informado de los milagros deste varón santo, y cobrando esperança embió a llamarlo, lleuando en que viniesse los que iuan por él. Llegan los mensageros. Suplícanle que vaya, y con el fauor que pudiesse echase aquel demonio. Al fin molestado de los ruegos, para mostrar el poder de nuestro Dios, no quiso ir en litera, sino a pie. Luego que llegó al lugar de Parpalinas que allí passaba el caso, se lo contaron todo: y aún él padeció allí sus molestias. Mandó que se ayunase, y ordenó que viniessen a él los Sacerdotes del pueblo. Llegado el tercero día, cumplido el ayuno que se auía señalado, bendixo sal, y mezclóla con agua, como lo usa hazer la Yglesia, y rozió con ella la casa. Luego el embidioso salió de lo secreto de la casa, y viendo que le echaban de su omenaje, començó a tirar pedradas al Santo: empero fortalezido con escudo fortíssimo, no se le dió nada. Al fin echando llamas con un abominable hedor, siendo ahuyentado se fue al desierto. $\mathrm{Y}$ assí los moradores de la casa quedaron gozosos, viéndose libres por la oración del santos.

En todos los casos el diablo - como ya ocurría en Prudencio- ocupa un espacio, sea el cuerpo humano o la casa, que el santo debe recuperar por el exorcismo.

Los signos de la ocupación diabólica son siempre la suciedad, el mal olor y el desarreglo gestual. La técnica del exorcismo es decididamente alopática:

5 Cito la traducción de la Vita hecha en el siglo XVII por el obispo Prudencio de Sandoval; una edición crítica del texto latino se debe a VÁzQUEZ DE PARGA, Vita Sancti Emiliani por Braulio, obispo de Zaragoza (Madrid: CSIC, 1943). 
disciplina, penitencia, ayunos y oraciones. En suma, purificación de un ámbito bien reglado, el corporal o el doméstico, que la presencia del demonio perturba: un orden simbólico dicotómico, excluyente.

Estas viejas historias de exorcismo, dentro de su simplicidad, nos indican ciertos supuestos vigentes en la época de Braulio al respecto del diablo y de la posesión. Por un lado, el diablo aparece siempre como un «contenido», sólo se revela bajo un continente humano, sea éste individual -el cuerpo- o colectivo - la casa-. Los signos que lo denuncian son alteraciones del gesto y la compostura, o resultados de ésta, como el olor. Sólo el santo, en el camino que va del yermo al poblado, ve al demonio en persona, como una entidad autónoma; el hombre normal lo incorpora, lo vive.

Por otro lado, el endemoniado es víctima pasiva e inocente de la posesión. El exorcismo le restaura en su ser legítimo atribuyendo una identidad diferente a la perturbación: así, los diablos que ocupan el cuerpo del siervo de Tuencio salen de él diciendo sus nombres. Como dice Prudencio, los crímenes del demonio no son crímenes del endemoniado.

Las posesiones enfrentadas por San Millán pertenecen claramente al tipo de las que I. M. Lewis llama "posesiones periféricas» ${ }^{6}$. Involuntarias como la enfermedad, forman parte de las tensiones existentes entre personas físicamente próximas, mas jerárquicamente distantes. El siervo y su señor, la esposa y el marido, la hija y su padre, el diácono sometido a clérigos superiores, la casa - que designa al conjunto de familiares y dependientesy el senador cabeza de la familia, etc. La intrusión del demonio supone una negación de las buenas maneras y de la obediencia, una rebelión que tiene la garantía de la irresponsabilidad. El endemoniado se sustrae parcial o totalmente a sus tareas cotidianas, agrede más o menos impunemente en nombre del diablo. Más aún, el proceso de exorcismo, la peregrinación al santuario en que será curado, obliga a gastos, coloca al poseso en el centro de las atenciones. Le saca, al menos temporalmente, de su sujeción. Apreciaremos la dimensión de esa revuelta si consideramos la escala en que acontece. La posesión es un fenómeno anormal pero muy corriente; forma parte, aunque marginalmente, de lo cotidiano. En el santuario, aún en vida de San Millán, la presencia de endemoniados es numerosa y común y fuente de mucha agitación:

[...] que acudiendo multitud de endemoniados, no solamente no mostraba el menor temor del mundo, mas se encerraba solo con todos ellos, donde quando con la divina gracia los había de curar, y muchas veces quando se iba a dormir, mostraban que le querían quemar: y hasta la cama llevaban la paja encendida y quando la aplicaban perdía el fuego la fuerça. $\mathrm{Y}$ en esto estaban trasnochando

6 I. M. LewIs, Ecstatic Religion (London: Penguin Books, 1978). 
sin hacer cosa ninguna, trabajando en vano. $\mathrm{Y}$ en sintiéndolo él, con andar todos sin juicio, se recogían: y en mandándolo él, se ataban unos a otros, y ocupaban las manos en hacer lumbre para calentarse, aun estando assí locos [...].

Ese desasosiego demoníaco es una dolencia benigna pero constante de la sociedad que nos describe el texto brauliano. En la mayoría de los casos se nos aclara que el santo se enfrenta con posesiones tenaces, que ya habían resistido otros intentos de expulsión; el margen social ocupado por el diablo era quizá considerable.

La posesión se presenta en una situación de contacto religioso - la evangelización era muy precaria en la zona- y en una sociedad rígidamente jerarquizada y dominada por una aristocracia celtorromana de patricios y obispos. Cristianismo y paganismo se identifican respectivamente con ciudad y campo. En la medida en que el cristianismo se impone en el campo, el paganismo se convierte en territorio diabólico y desterrado al yermo. La posesión no es el único fenómeno que perturba el orden de esta sociedad. Existe -esporádica y recurrente- la bagauda, una revuelta campesina que vacía las haciendas y lleva a los siervos al vagabundeo y al pillaje. A veces en proporciones políticamente temibles: es el caso de la bagauda que recorre el valle del Ebro y mata en el 449 al obispo de Tarazona junto con su guardia, y va a unirse después a las tropas de un rey bárbaro ? . La misma vida eremítica, en este período anterior a la reglamentación de la vida monástica, es un fenómeno muy ambiguo. No pocos siervos abandonan las ciudades o las tierras de sus señores para habitar en yermos alejados, en las sierras. La Vita Sancti Emiliani nos narra que el propio santo era un pastor de ovejas que abandonó el rebaño para entregarse a la vida ascética. En la periferia de los núcleos romanos de la región estudiada encontramos casi siempre - aún visibles hoy en día y a veces habitadas hasta años recientes- «tebaidas» de difícil acceso, a las que los historiadores llaman comúnmente «eremitorios» capaces de albergar una población crecida. Tal vez para entender quién vivía en aquellos eremitorios deberíamos olvidar un poco las hagiografías y pensar en la numerosa marginalia rural del mundo tardorromano.

Esta digresión nos servirá para definir mejor nuestro tema central. Si el culto a los mártires era patrimonio de un patriciado cristiano al que Prudencio pertenecía, la consagración por parte del obispo Braulio de un santo ermitaño supone una maniobra más audaz: recluta el santo en el propio hontanar de la perturbación «diabólica», el agro apartado del orden cristiano. Asimila una figura rústica y marginal, cuyo cristianismo debe ser por lo

7 J. J. Sayas Abengoechea y L. A. Garcfa Moreno, Romanismo y Germanismo (Barcelona: Labor, 1982), p. 152. 
menos rústico y marginal, y presumiblemente sincrético. El exorcismo es un poder del santo de la ciudad como lo es del santo del campo, pero si en el caso de los mártires representa la coronación de una historia ejemplar, en el del santo ermitaño se constituye en la historia misma.

La creación del santo y del demonio - o la cooptación de uno y otro, en la medida en que ya existiesen en el mundo precristiano- amplía así el dominio simbólico de la Iglesia. La posesión diabólica, en una situación de contacto religioso, supone paradójicamente una conversión. La persona es controlada por una entidad sobre la que la Iglesia y sus santos tienen a su vez control.

Los santos mártires están próximos al «centro» del cristianismo, por el que han muerto, reproduciendo el sacrificio de la cruz. El santo ermitaño, en el margen de la sociedad, es santo simplemente porque combate a un contrario. La hagiografía de Braulio es pionera: carece de una elaboración amplia de los modelos de santidad y diabolicidad, y por eso carga todo el acento en la frontera, en la oposición entre ambos.

\section{EL DiABLO EN ROMÁN PALADINO}

Sobre la memoria de San Millán, y después de vicisitudes históricas que no hacen mucho al caso, se asentó un poderoso monasterio que llevaba y aún hoy lleva su nombre. En el siglo XIII este monasterio era sede de un activísimo escritorio, que frecuentó el primer poeta de nombre conocido que escribió en lengua castellana —en «román paladino» según propia declaración: Gonzalo de Berceo.

La producción de Berceo fue bastante amplia, y se dirigió sobre todo a la difusión de la doctrina cristiana y de cultos especialmente promovidos por la Iglesia, como el de la Virgen María. También se dedicó a santos vinculados al monasterio, como Santo Domingo de Silos o Santa Oria, y, sobre todo, el propio San Millán. Berceo no inventaba sus argumentos, y son bien conocidas por los especialistas sus fuentes: hagiografías o colecciones europeas de exempla en latín. En el caso de la Estoria de Sennor Sant Millán ${ }^{8}$, la fuente es el ya citado texto de San Braulio. Comparar los textos de San Braulio y Berceo es algo sumamente sugestivo. El segundo triplica por lo menos la extensión del primero; mas puede decirse que le es fiel. Berceo reproduce los combates o las posesiones diabólicas narrados por San Braulio adjetivándolos, pero sin añadir aparentemente nuevos datos ni incluir nuevas interpretaciones. Es posible inferir que el fenómeno de

\footnotetext{
8 Cito por Gonzalo de Berceo, Obras completas (Logroño: IER, 1981).
} 
la posesión sobrevivió durante siete siglos con la estabilidad suficiente para no requerir actualización, para ser vivamente comprendido por el oyente.

\section{El Diablo y la Bestia}

Sin embargo, hay algunas excepciones a esta fidelidad. La primera es una novedad absoluta de Berceo. Cuando San Millán se retira a vivir en el yermo, lo encuentra terriblemente habitado:

Serpientes e culebras avíen en él hostal.

Estaban grandes pennas en medio del vallejo, avíe de jus las pennas cuevas fieras sobejo

Vivíen de malas bestias en ellas grant concejo

Era por end grand siesta un bravo logarejo. (Cuartetas 27-28).

El santo no se arredra, sin embargo, y se queda a vivir en las cuevas:

Fueron las bestias fieras con él fuertment embargadas,

Todas fuyien atelli las cabezas colgadas,

Si les plógo o non, cambiaron las posadas...

Otras cosa retraen, mas non la escribieron,

Hí muestran los forados que las sierpes fiçieron,

Las pennas foradaron, quand ficar non podiéron,

Pero al omne bono nul pavor nol fiçieron. (Cuartetas 30 y 31 ).

El texto de San Braulio constataba secamente la permanencia del santo en las ásperas sierras. ¿Qué son estas sierpes y de dónde salen?

Podemos contestar con una aparente perogrullada: son sierpes, más o menos adjetivadas.

Es decir, no son demonios. Los mitos de origen de santuarios vecinos - Nuestra Señora de Valvanera, la Virgen de Lomos de Orios, San Vítores de Cerezo- incluyen con frecuencia historias semejantes, en que una gran serpiente desaloja el lugar que va a ser ocupado por el santo, con mayor o menor coacción, y a veces abandonando pacíficamente el campo.

En otros casos se trata de otro tipo de animales (osa en Santa Coloma o leona en Santa Casilda, santuarios también próximos) cuya actitud oscila entre ese limitado enfrentamiento con el santo y la franca colaboración con él. Actualmente se cuentan todavía, respecto de Valvanera y Lomos de Orios, relatos que muestran la insalvable distancia entre el hombre y el reptil. Un pastor cuida y protege una serpiente joven. Cuando la reencuentra después de una larga ausencia se ha convertido en un monstruo feroz, de quien sólo la inetrvención de la Virgen consigue salvarlo. 
Es tentador pensar que la innovación de Berceo es de origen popular/oral, lo que él mismo sugiere. La popularidad del episodio de la serpiente en la cultura campesina moderna podría ser engañosa, pero es probable que si éste procediese de fuentes cristianas «cultas» compartiría la interpretación diabólica que la doctrina daba al episodio del Paraíso. No es éste el caso. Es muy común encontrar en antiguos santuarios españoles cueros de serpientes, o serpientes disecadas, ofrecidos como presente, o como exvoto, muchas veces por devotos que se habían encontrado tales prodigios de la naturaleza en las Indias Occidentales. En el Santuario de Valvanera existe una de éstas, en una ermita cecana al monasterio. En alguna ocasión he oído identificarla con la serpiente con que el ermitaño Nuño, constructor del lugar, se enfrentó. Pero también puede referirse a ella este texto:

Por los añoos de 1570 [...] un pastor desse convento entró por la puerta de la Iglesia tan apresurado y atónito que todos le hizieron lugar [...] y a vozes daua gracias à la Virgen de Valvanera; porque por ser criado suyo le auía dado fuerças para que con el cayado huuiesse matado al demonio, y que si lo querían ver le fuessen siguiendo hasta el río [...] siguiéronle algunos, y al llegar al río vieron una espantosa serpiente de cinco varas de largo, la cabeza grande, y terrible, las escamas como si fueran de azero, los dientes monstruosos, las alas con pinturas de medialuna, y la cola partida por medio [...] y aún estaba agonizando revolcándose en la arena, arrojando sangre por la boca, por donde la había herido el pastor con la punta del cayado. Admirados del sucesso la acabaron de matar, y la truxeron al convento [...] y colgaron la piel en el Claustro Santo, que hoy se conserva ${ }^{9}$.

La identificación de serpiente y diablo, aún en el siglo XVI, es posible, pero en cualquier caso secundaria, y por eso la interpretación del pastor no fue muy tenida en cuenta. Lo que cuelga allí no es un diablo, sino un monstruo de la naturaleza.

El afán de interpretar puede llevarnos, de todos modos, a insistir. Si esas serpientes no eran diablos, podían ser al menos divinidades precristianas, o transformaciones de éstas. Es bien sabido el carácter sincrético del catolicismo mediterráneo, o del catolicismo en general, su estrecha vinculación con el paganismo que le precedió. Algún ser más o menos divino era, de hecho, adorado en el lugar antes de la cristianización. Se ha encontrado un ara de época romana dedicada a un «Deo Dercetio» ${ }^{10}$, presumiblemente céltico e identificado con el monte Distercio, más tarde - y

9 D. de Silva y Pacheco, Historia de la Imagen Sagrada de María Santísima de Valvanera..., milagro 86.

10 José M.: BLÁZquEZ, Diccionario de las religiones prerromanas de Hispania (Madrid: Istmo, 1975). 
hasta ahora - bautizado con el nombre de San Lorenzo. Pero ese probable sincretismo inaugura, en cualquier caso, una situación poco permeable a la «pervivencia». Si demonios y serpientes cobijasen una sustancia precristiana sería lícito esperar que ésta se manifestase mejor en documentos más antiguos. Pero, muy por el contrario, es ya en plena Edad Media y de camino al Barroco cuando unos y otras van ganando fuerza y definición ${ }^{11}$. A falta de testimonios que indiquen la continuidad de una mitología pre-cristiana, es arriesgado suponerla: más vale admitir que lo que continúa es la capacidad de fabular de la población rural, que actuó en el cristianismo como actuó en épocas anteriores.

En los mitos de los santuarios riojanos, en suma, aparece con frecuencia un episodio de animales, ajeno al corpus doctrinal y también a la demonología de la Iglesia. Son narraciones que, más que con ninguna mitología cristiana o precristiana, tienen que ver con la concepción del espacio y de la naturaleza de los campesinos. Basta ver la estrecha relación de los santuarios actuales con los accidentes geográficos - y especialmente con montañas como el mismo San Lorenzo- para reconocer hasta qué punto una representación mítica de la naturaleza es necesaria en la religión rural. Tan importante en ella como periférico y tolerable para la religión de los clérigos. La serpiente aparece en esa religión rural como un símbolo del distanciamiento extremo de la naturaleza frente al hombre. Que el diablo no se haya identificado con la serpiente, a pesar de que en el cristianismo existía una tradición interpretativa favorable a ello, querrá decir que la oposición hombre/naturaleza es casi irrelevante en la definición de la figura del diablo que se opera en la Edad Media.

Pero esa última afirmación puede ser prematura. Si parece descartado el carácter diabólico de las bestias, deberemos aún aclarar el carácter bestial del diablo. En la ocasión en que Berceo presenta un diablo «en sí», independiente de cuerpos o casas -es decir, cuando narra el enfrentamiento cuerpo a cuerpo de San Millán y el Diablo- emplea para describirlo una expresión paradójica: nos dice que «la bestia maledicta» tomó «humanal figura» (cuarteta 112). El diablo depende siempre de la figura humana para materializarse, aun cuando se suponga que su verdadera naturaleza sea animal. Berceo tenía un referente plástico que de algún modo le contradice. Uno de los marfiles de la arqueta de las reliquias de San Millán representa ese combate, y en él, como en otros en que el diablo aparece, su figura

11 J. LE GOFF, en Lo maravilloso y lo cotidiano en el Occidente medieval (Barcelona: Gedisa, 1985), comenta que el mundo imaginario del cristianismo altomedieval es extremadamente sobrio, racionalista; sólo en el siglo XIII la cultura fantástica se abrirá un espacio importante dentro del cristianismo. 
está muy lejos de ser humana, con cuernos, rabo, alas y garras. Es una tradición plástica del Oriente Medio que se consagra en el románico y que sólo a partir del renacimiento sufrirá la competencia del modelo grecorromano del fauno o sátiro, mixto humano-cabrío. Las otras representaciones que conozco de los diablos de San Millán son las de un díptico no muy posterior a Berceo, que estuvo colocado durante siglos tras el altar principal del monasterio. Allí, los diablos son representados como una especie de minotauros, de cuerpo humano y cabeza de toro, y de color negro.

Es digno de atención que una imagen tan caprichosa haya tenido el éxito suficiente para continuar pareciéndonos algo así como el retrato oficial de Satán. Tal vez podemos entenderla mejor en comparación con esa serpiente, cuyo carácter diabólico se negaba anteriormente. La serpiente está a una gran distancia del hombre: carece por completo de extremidades. La figura «románica» del diablo es, en sentido opuesto, una figura humana a la que se añaden extremidades inhumanas, prácticamente todas las que pueden hallarse en el mundo animal, a excepción del pico de los pájaros - puede ser que por la importancia que tiene el que el diablo hable. El mismo Berceo, en otro texto, concretamente en el n. Xx de los Milagros de Nuestra Señora, narra la aparición del diablo en forma de toro, de perro y de león. Tres siglos más tarde, en un milagro de Valvanera datado en $1550^{12}$, nos encontramos con una sucesión pareja de transformaciones. A Miguel López se le aparece el diablo tres veces. La primera, en forma de un perro negro que habla. En la segunda varió mucho: primero una «mujer hermosa», después un «hombre galán», pero por fin se dejó llevar de su ser horrible, y mostró «espantosa apariencia, la más fea y formidable». En la tercera y última ocasión, se muestra en el campo como un remolino de polvo.

Debo señalar que no hay ningún valor fijo en esas transformaciones. León, perro y toro, que recuerdan los ribetes bestiales del «diablo románico» son en otros contextos símbolos de santos. León y toro son símbolos de evangelistas, concretamente de San Marcos y San Lucas; la tradición popular española tiende a identificar el toro con San Marcos. El mismo perro, que frecuenta con asiduidad las listas de animales inmundos (y no se olvide que en portugués cão es el apodo más común del diablo) puede representar a Santo Domingo de Guzmán, cuyos descendients no dudaban otrora en bromear llamándose Domini canes, es decir, perros del Señor.

Es decir, mientras que los animales pueden ser emblemas, símbolos fijos de los santos, el diablo está comprometido no con el animal en sí, sino con la metamorfosis. Cuando adopta formas animales, raramente se limita

12 D. de Silva, op. cit., milagro 67. 
a una sola: transita entre varias, o reúne en una aparición caracteres de animales diferentes. Esta figura mixta es lo que puede entenderse por «mostruo», palabra que a falta de otra más concreta se aduce a veces como «verdadero ser» del diablo que se revela después de otras apariciones ilusorias, como ocurría con Miguel López ${ }^{13}$.

El imaginario medieval busca una expresión concreta de la «sobrenaturalidad»: el diablo consigue la sobrenaturalidad por acumulación de atributos naturales. Su poder se compara a la fusión de las capacidades motoras y agresivas de todas las bestias. La tarea de imaginar a Dios no era, en el fondo, tan diferente. Pleno de atributos abstractos y carente de cualquier atributo físico, Dios, puesto a encarnar, puede mostrar la misma volubilidad del diablo. Véase, si no, el ejemplo de Guillermo de Ockam, para quien la omnipotencia divina podría haber dispuesto que el Hijo de Dios se encarnase en forma de asno. Representantes de un dios demasiado sutil, los evangelizadores medievales dijeron más y mejor del Diablo que de Dios. El Diablo quedó por ello como una especie de garante de Dios, prueba y huella de Él.

\section{Diablo y Sociedad}

Queda examinar otra de las infidelidades de Berceo con respecto al texto de San Braulio. Ya conocemos la narración latina sobre el alboroto que los endemoniados hacen en la morada del santo. Berceo saca de ese fragmento infinito provecho a lo largo de veintiuna cuartetas (de la 212 a la 222). El santo dormía con los endemoniados, cuyas «malas figuras» no hacían mella en su ánimo ni en su sueño. Los diablos, entonces, deciden hacer «su concilio» para «levantar capítulos y constituciones» para «tratar de su regla» y «reformar los vicios que avíen oblidados». En tal reunión, manifiestan sus quejas del santo. Cada uno de los diablos que San Millán ha expulsado o vencido habla a la asamblea, promoviendo una venganza, y por fin se decide que todos irán por el monte a buscar haya seca y brezo añejo para quemarlo por la noche mientras duerme. Cuando intentan poner fuego a la cama del santo, sin embargo, los planes se tuercen: las llamas se desvían y queman a los mismos diablos, que se creen agredidos por alguno de sus

13 Los monstruos y las «fieras corrupias» del romancero de cordel están construidos según un modelo de rompecabezas similar al del diablo, pero apartándose del eje humano y juntando los disiecta membra sobre un armazón de serpiente; considérense, por ejemplo, los presentados por J. Caro BAROJA en su Ensayo sobre la literatura de cordel (Madrid: Rev. Occidente, 1969). 
compañeros de conspiración. En fin, se arma entre ellos tan gran confusión como no hubo en Babilonia, explica Berceo:

Firíense por los rostros a grandes tizonadas

Traýen las soberçeias sangrientas e quemadas,

Las frentes mal batidas, las barbas socarradas, ...

Prisiéronse a pelos e a los cabezones,

Dándose espoladas e fuertes aguiiones... (cuartetas 220-221).

El santo despierta entonces:

Levantó la cabeça, cató en derredor,

Vió esta revuelta, entendió el fervor,

Por poco se non riso, tant ovo grant sabor (cuarteta 222).

Se trata de la mayor improvisación de Berceo, y de ella cabe decir muchas cosas.

Primero, sustituye unos protagonistas humanos, los endemoniados, por diablos propiamente dichos. En los marfiles del arca, del siglo XI, la escena está a medio camino entre San Braulio y Berceo: las figuras se atacan entre sí, como cuenta Berceo, pero son todavía hombres, como en San Braulio. Ya en el díptico gótico antes citado, posterior a Berceo, se trata de diablos. Segundo, no sólo se cambia - por sinécdoque, digamos- la identidad de los protagonistas, sino que se inventa toda una asamblea diabólica. Vamos a detenernos en este segundo punto antes de evaluar el primero. Parece ser que Berceo elaboraba sus poemas para un consumo «mixto»; escritos, pero para ser leídos ante una audiencia. El fragmento analizado-burlesco, dialogado, un tanto chocarrero- parece en este sentido un punto fuerte de la narración en conjunto, apto para hacer reir al público, como casi lo hace el santo. Aunque pudiera tener fuentes literarias independientes de San Braulio, está fuertemente anclado en el universo local. San Millán era entonces un dominio absoluto de los benedictinos, y la asamblea diabólica parodia un capítulo general de monjes. Es decir, entre burlas y veras se propone al público una visión política del universo diabólico. Berceo, que ha reproducido fielmente los relatos braulianos de las posesiones, recapitula aquí todos los demonios anteriormente exorcizados. Los saca del cuerpo humano y les da cuerpo propio, citado en medio de la refriega. Más aún, los constituye en sociedad. Berceo adopta un recurso que podríamos llamar «durkheimiano» para caracterizar lo diabólico, imaginando una sociedad de diablos que reproduce, en una inversión simétrica, la sociedad monacal: los diablos tienen capítulos, escriben reglas y constituciones, pero su código moral está invertido, y deben hacer esfuerzos para mantener la pureza de sus vicios. 
Sobre la constatación «empírica» de la posesión diabólica se levanta entonces una teoría sobre el diablo que no es ya la teoría metafísica y moral de San Agustín, que se preocupa de la existencia del Mal, sino una teoría sociopolítica que se preocupa de su organización. En época no muy posterior a Berceo existe ya una demonología activa que interpreta como estrategias diabólicas las disidencias políticas y sociales, y que busca por todas partes evidencias de la mafia satánica, con los resultados que bien conocemos ${ }^{14}$. El concejo diabólico consigue pasar de la literatura a la realidad: se cree en él, se sueña con él. Ya en el siglo XVI, la democracia frailuna de los diablos habrá dejado paso a la monarquía de Lucifer, y el Sabbath, con su misa al contrario y su castigo de los pecadores flojos, continuará suministrando una inversión de las pompas y las obras de la sociedad cristiana.

El diablo berceano no se agota en esta sociedad diabólica. La conversión del endemoniado en demonio que él anuncia tendrá amplios resultados. Una de las características que Lewis atribuye a la posesión «periférica» es su falta de significación moral, que permite la utilización táctica de ese fenómeno en los conflictos interpersonales ${ }^{15}$. Pero no tarda mucho en llegar un elemento nuevo, que muda este cuadro y traslada el diablo de la periferia al centro de la preocupación religios. Berceo, en el número XXIV de los Milagros de Nuestra Señora, nos cuenta la historia de Teófilo, primer avatar en lengua castellana de una de las más comentadas carreras literarias de Occidente.

Teófilo, hombre piadoso, vicario del obispo de su ciudad, es injustamente desposeído de su cargo por el nuevo obispo que llega a la muerte de aquél. Ciego de rabia recurre a un hechicero judío, quien le conduce a una encrucijada desierta. Allí aparece una misteriosa comitiva cuyo Rey presenta el judío a Teófilo. A cambio de una promesa de restitución, Teófilo firma un papel en que reniega de Cristo y de Santa María. Teófilo vuelve a su casa, y no tarda el obispo en devolverle su cargo; pero se siente enfermo y angustiado por causa de su pecado, y no osando dirigirse a Cristo pide ayuda a Santa María. Ésta, no sin hacerse mucho de rogar, intercede ante Cristo por Teófilo e incluso va a los infiernos a recuperar el documento. La historia acaba con la confesión pública de Teófilo, la quema del contrato diabólico y la piadosa muerte del protagonista.

De nuevo son modelos sociales los que dan mayor sustancia al universo diabólico. El pacto diabólico que siglos más tarde tomará la forma de venta

14 Ver, por ejemplo, Norman CoHN, Los demonios familiares de Europa (Madrid: Alianza U, 1975).

15 I. M. LEWIS, op. cit. 
del alma aparece aquí como ruptura del vasallaje debido a las figuras divinas. Lo más importante, con todo, es el cambio de sentido de la relación entre hombre y diablo. En los relatos de San Millán, el hombre, que pertenece a un mundo santificado, es invadido a veces por el demonio, y realiza por ello actos indebidos de los que él mismo no es responsable. Teófilo, por el contrario, sale al encuentro del diablo, y él mismo es responsable, no por actos reprobables - que no los hay- sino por la simple relación establecida con la «ueste antigua». El hombre queda así en la encrucijada de dos universos sobrenaturales que le reclaman: el exorcismo ha despachado al demonio, pero ha dejado entrar la conciencia moral.

Ampliemos el contexto. Milagros de Nuestra Señora es la obra más alabada de Gonzalo de Berceo. Se trata de la adaptación castellana de una serie de historietas marianas en latín de las que existen numerosas versiones. Las Cantigas de Santa María, de Alfonso el Sabio escritas aproximadamente en la misma época, incluyen 19 de los milagros narrados por Berceo, si bien con variantes que sugieren alguna diferencia de fuentes. Existía un enorme interés, por parte de la Iglesia y los monarcas, en difundir el culto de la Virgen, y esto tal vez —es una hipótesis - para dar cierta homogeneidad a un cristianismo atomizado en el culto a santos locales. Junto a la divulgación poética de Berceo y Alfonso, se fundan numerosos santuarios dedicados a la Virgen, o se introduce su veneración en lugares de culto ya existentes.

El mensaje transmitido por la propaganda mariana es peculiar. Los Milagros de Berceo, paradójicamente, están más cerca de algunas sátiras antirreligiosas del XVIII que de literatura edificante más moderna. El culto mariano se propone como algo primordialmente amoral, como un sacrum por encima del bien y del mal. Hay, sí, pobres inocentes socorridos por la santa Señora, pero hay sobre todo clérigos borrachos o fornicarios, ladrones sacrílegos, peregrinos vividores y - como hemos visto- políticos capaces de pactar con el diablo por un cargo. Todas estas personas moralmente condenadas tienen, sin embargo, algo en común: profesan una devoción, tal vez anecdótica pero en cualquier caso constante, por la Virgen. El fraile fornicador, por ejemplo, no pasaba nunca ante la imagen de la Virgen (incluso yendo y viniendo del fornicio) sin una inclinación: esta delicadeza le vale al pecador la omnipotente protección mariana ante el supremo juez. En la versión católica vigente ahora, María es la intermediaria entre los hombres y Dios. En los textos de Berceo, sin embargo, ese Dios o ese Cristo no aparecen como personajes, aun cuando se aluda a ellos con frecuencia; por el contrario, son numerosos los diablos. Además del diablo que persigue al monje ebrio en figura de animales, y del Rey Diablo de Teófilo, tenemos un diablo que se hace pasar por Santiago Apóstol y catervas de 
diablos que reclaman a los pecadores para llevárselos al Infierno. El diablo aparece con un perfil moderno en comparación con el que examinábamos al principio de este trabajo: dispone de un universo propio -el Infiernobien organizado, y con unas reglas que regulan su relación con el hombre y la divinidad. Ha dejado de ser margen, presencia liminar, para ganar un centro, un territorio propio que cada vez estará más presente en las preocupaciones humanas. La intermediación de la Virgen, en suma, se ejercita preferentemente entre el mundo moral humano y su contrafigura, el mundo diabólico. La Virgen gana así un peso real muy superior al de las otras figuras sagradas, porque relativiza la oposición excluyente de bien y mal, y con ello acrecienta el valor de la relación personal con una figura poderosa. Tal vez no es por acaso que el culto de la Virgen se difunde en Castilla al mismo tiempo que algunos modos del feudalismo clásico, en el siglo en que se extiende el poder de los reyes.

En Berceo el espacio diabólico es aún débil: señálase, por ejemplo, que el pacto de Teófilo con el diablo es inoperante: la suerte de Teófilo sólo depende de la voluntad de Dios. En siglos ulteriores, los teólogos atribuirán a Satanás poderes mucho más amplios; inicia esa tendencia Santo Tomás de Aquino, que reivindica la realidad del diablo y de sus poderes, y que condena como falta de fe el escepticismo a este respecto ${ }^{16}$. La especial vinculación del judío con el diablo, del mismo modo, no es sino el primer paso de una demonización colectiva de la raza, que irá tomando mayores proporciones en el futuro. Pero lo que es más importante señalar ahora es que el Diablo y la Virgen, personajes de orígenes muy diferentes, se popularizan juntos en la propaganda religiosa medieval y juntos se inician como personajes literarios. Poco a poco, pasarán de la literatura a las visiones cotidianas.

\section{LOS DESCAMINOS DEL ALMA}

\section{Los diablos de Valianera}

Valvanera es, a fines de la Edad Media, un monasterio benedictino y un centro regional de peregrinación. El objeto de esta peregrinación era -y es aún hoy en día - una imagen de la Virgen probablemente del siglo XI (fig. 1). Los milagros operados por la imagen fueron anotados en una lista existente en el monasterio. Las fechas más antiguas registradas son de 1428, y se extienden por el siglo XV y sobre todo el XVI y comienzo del XVII. Desconozco si la lista original - similar a la que mantenían con orgullo

\footnotetext{
16 Apud J. Caro Baroja, Las brujas y' su mundo (Madrid: Alianza, 1973), p. 109.
} 


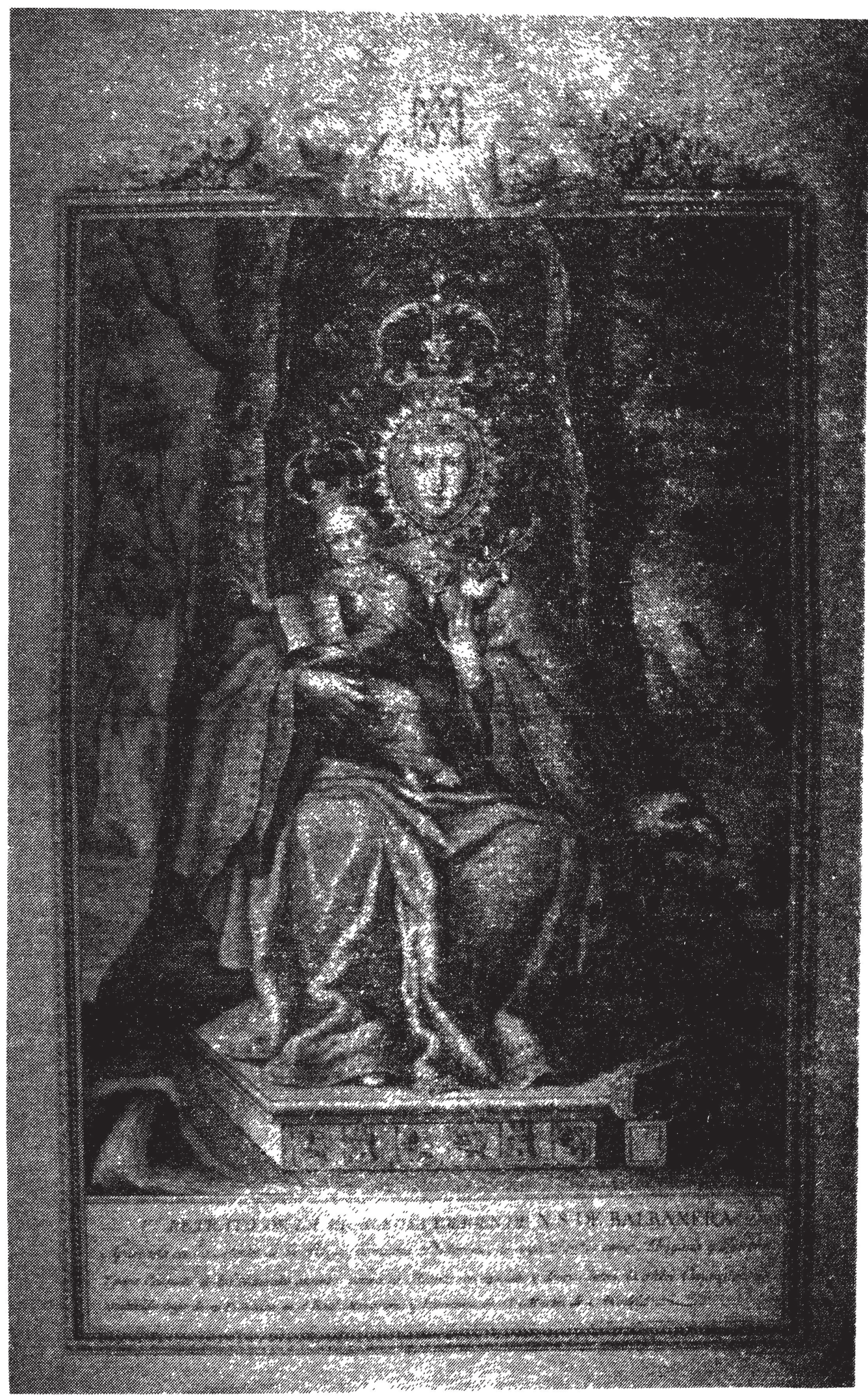

$1:$

(c) Consejo Superior de Investigaciones Científicas 
todos los santuarios de alguna importancia - se conserva. Me baso en la copia que, como apéndice de su libro sobre el santurio, publicó en 1665 Silva y Pacheco ${ }^{17}$. Este autor ensambla, al parecer, varias listas independientes, por lo que la sucesión numeral de los casos no siempre guarda un orden cronológico. El texto debe ser leído con algunas precauciones: Silva trascribe directa o indiretamente, cita y refunde, añadiendo glosas de su cosecha. La presencia del propagandista barroco, una vez tenida en cuenta, más realza que perjudica el valor documental de estas narraciones.

Varios milagros de la lista nos hablan de endemoniados: los numerados $24,71,77,80,87,89,114,119$ y 136 . El número 119 , de 1627 , es el segundo texto presentado en la introducción, y muestra la constancia del viejo modelo de posesión, a pesar de la diferente selección de datos operada en uno y otro caso. Podemos comparar en un cuadro las características de la posesión diabólica y su cura tal como era observada en Prudencio, en San Millán y Valvanera:

\begin{tabular}{|cccl|}
\hline Prud & SM & Valv \\
+ & + & + & El demonio está dentro de la víctima. \\
+ & + & + & Convulsiones, desarreglo. \\
+ & + & + & La víctima es llevada a un santuario. \\
- & + & + & Duerme en él varias noches. \\
- & + & + & Se le aplican oraciones. \\
+ & + & + & El diablo se queja. \\
+ & + & + & Demonio habla al salir \\
+ & + & - & identificándose. \\
\hline
\end{tabular}

Para descripciones someras como las que estoy aquí manejando, se trata de una notable estabilidad. Las liturgias aplicadas al exorcismo pueden variar según los usos de la época, pero lo fundamental es la presencia de las reliquias o de la imagen sagrada, que empujan al demonio fuera del cuerpo.

Ahora bien, los milagros de Valvanera incluyen, junto a esas posesiones clásicas, otros fenómenos que muestran una leve variación:

En el lugar de Cordobín de Valdecañas, Catalina Cordobín era perseguida del demonio, con horribles, y espantosas visiones, con tanto estremo, que la muger casi atónita, no podía governar sus acciones, y temía el peligro de su vida en muchos riesgos, que ocasiona essa desdicha, cuando turba la razón, y ocupa las potencias todas. No hallaron remedio alguno a esta enfermedad [...] sino buscar de la Virgen

17 Otros autores que escribieron historias del santuario, como Bravo de Sotomayor y Benito Rubio, tienen también sus listas de milagros, pero la de Silva y Pacheco es la más extensa que conozco, e incluye las otras. 
de Valvanera el amparo [...] Y acabada la oración se sintió la muger sana, quieta la cabeza, y nunca más las ilusiones la acometieron $[\ldots]^{18}$.

Lo que describe aquí no es ya la entrada de un diablo en el centro regente del individuo, que pueda solucionarse con su expulsión, sino una aproximación del diablo que perturba el entendimiento de su víctima, y que exige apartar, ahuyentar al diablo, como se indica en el milagro 80 :

En el lugar de Torralba en el Reyno de Navarra, Catalina de Torralba padecía de el demonio terribles fatigas, atormentava su cuerpo, y le afligía el alma, y no hallando a tanto mal remedio, pidió que la truxesen en romería a este Santuario; y luego que entró en la Iglesia, ofreció de nueve días la estación, y al fin la Virgen desterró al demonio, atándole en los desiertos, para que no pudiesse ofender $[\ldots]^{19}$.

Son variaciones sutiles que desdibujan aquel modelo previo de posesión. Por un lado, el asedio - ya no la invasión- del diablo ocasiona una serie de males que se asemejan más a una «enfermedad» que a una «posesión». La misma posesión, por otro lado, puede presentarse como fruto de una perturbación anímica de otro tipo:

En el concejo de Ahedo [...] Gabriel de la Rebilla estaba apacentando unos bueyes, y se le pusieron delante tres hombres en la apariencia de feroz aspecto, y horrible presencia, y el uno le asió del braço, de que concibió tanto miedo y espanto que cayó en tierra sin sentido; y quando volvió en su acuerdo, sintió que le atormentaba un espíritu maligno $[\ldots]^{20}$.

Es el caso de María Cabredo (milagro 114), que en 1625 «de una fantasma que vio, se halló endemoniada [...] su marido la ofreció a Nuestra Señora de Valvanera, y la truxo a su Santuario; y después de conjurada se sintió aliviada; pero a la noche dando una voz espantosa, quedó libre, y dixo gracias à Dios, y à la Virgen de Valvanera, que me ha librado».

Es el caso también del labrador de Huércanos del milagro 9, datado por Silva en 1599. Pasando por la vecina ciudad de Nájera ve un hombre ahorcado. Obsesionado por la horrenda imagen, que no le abandona, se ve tentado por el diablo al suicidio. Su familia, después de mucho verlo sufrir,

18 D. de Silva, op. cit., milagro 77.

19 Aunque no aparezca en el texto de Prudencio, la «incubación», el rito de hacer dormir al afligido durante varias noches en el santuario, cuenta con una tradición terapéutica pre-cristiana -el caso más clásico de su uso es el del templo de Esculapio en Epidauro- y fue antaño una práctica absolutamente común en los santuarios católicos, sobre todo en forma de novena.

20

D. de Silva, op. cit., milagro 99. 
lo lleva a la fuerza - porque el diablo en su interior se resistía- a Valvanera, donde al final se cura, entre gritos y llantos propios y de toda su familia.

En suma, a fines del siglo XVI, en un santuario que alcanza en esa época su mayor influjo, los casos de afectados por el diablo son numerosos, pero muestran una tipología mucho más compleja y abierta que la de San Millán. Junto a las posesiones diabólicas clásicas, que toman el cuerpo humano y lo sacuden de su ajuste social, tenemos una acción diabólica que viene del exterior y desajusta el alma del individuo. La figura del diablo ha conquistado en la realidad el grado de autonomía y concreción que tenía en la literatura de Berceo: es un personaje de la vida cotidiana, y sus acciones son otras. No se nos habla ya de suciedad, mal gesto, aspecto bestial: lo que el diablo induce son visiones, sueños, delirios, sólo cognoscibles por la confesión de quien los padece.

En otras palabras, el encuentro con el diablo se ha convertido en una experiencia interior, para cuya descripción se emplea un léxico psicológico cada vez más rico. Las glosas que Silva, en 1665, aplica al caso del obsesivo labrador de Huércanos nos dan una muestra:

[...] la vista horrible se imprime más fuertemente en la imaginación que las imágenes que comúnmente se miran [...] obró aquél espectáculo mortal en la fantasía del passagero una impresión tan presente [...] que no la pudo apartar de su idea [...] al modo que los espíritus en el horror del infierno sienten la pena insufrible, y la llaman del sentido, porque obra el entendimiento en la aprensión del lugar, de las llamas, con tanta disconveniencia [...] que es martirio verdadero. Así el triste labrador, afligido de la imagen del suplicio [veía] en sí mismo una forma de dolor [...] y un pavor de un ahorcado. El demonio [...] porfió con sus ideas fijas siempre [...] el espanto le tenía fuera de su discreción, como atónito, sin discurso para gobernar sus obras $[\ldots]$ sin juicio, rematado el entendimiento $[\ldots]^{21}$.

En la opinión de un clérigo como Silva, el diablo es ante todo una «cosa psicológica», más cerca de la idea que de él se haría un librepensador moderno que de la que Santo Tomás proponía. Si antes hemos visto una historia del diablo inseparable de las oposiciones entre grupos sociales, aquí se muestra como un fermento del alma individual. No hay condiciones aquí de contribuir a una historia española de la locura, entre otras cosas porque para ello hay veneros documentales mucho más ricos que los ahora manejados. Pero no podemos olvidar tampoco que los milagros narrados ocurren en su mayoría en un siglo en que comienza a imponerse la categoría de «enfermedad mental».

21 Ibid., milagro 9. 
En la lista de milagros de Valvanera, «endemoniado» y «loco» son categorías que no se confunden. Los locos son también bastantes. Los milagros hablan de once casos. Un militar, en el milagro 37, es víctima de una «locura y manía» sin especificar. La mujer del 16 corre desnuda por las calles, y la del 90 está melancólica, sin ánimos. En todos los otros casos, nos encontramos con «locos furiosos» muy parecidos entre sí. Así, el loco del milagro 14 «era espanto de todo el pueblo, y aunque con grillos y esposas le tenían siempre atado, era tan bravo y feroz que nadie se assegurava, huyendo todos desta fiera sin discurso [...] con fuertes grillos, y atado le pusieron en presencia de la Imagen de María, y haciendo de nueve días la costumbrada estación, al fin dellos començó el hombre a estar manso [...]».

O si no, Martín Ladrón, de Vitoria, que «adoleció de una enfermedad de locura tan recia, y de tanto furor, que sólo podían tenerle atado, porque no se despedazasse con la furia del achaque [...] le truxeron a este Convento, con no pequeño peligro por la terribilidad de la enfermedad [...] [y al cabo de nueve días] quiso la Magestad de los cielos que se sossegasse el celebro, y cobrasse entero sentido, y que cesasse el furor [...]».

Quiero hacer notar algo: en todos estos casos volvemos a encontrar la espectacularidad física que caracterizaba a los endemoniados «clásicos». Transcurren, además, en una época en que la posesión demoníaca está aún presente. Es más, la semejanza entre ambos fenómenos es bien percibida:

El mismo año [de 1628] Iuan Pannero, vezino de Viniegra de Abaxo, adoleció de una profunda melancolía, causada de haver perdido mucho caudal por la baxa de la moneda: era con tanto estremo, que desesperado se dava golpes por las paredes, y buscava con que ahorcarse, o río donde ahogarse: $y$ como endemoniado aborrecía todas las acciones de Christiano, tanto que fue necessario atarle, porque no se desesperase. $\mathrm{Y}$ desta suerte $[. .$.$] le llevaron a Valvanera [. .$.$] que le dio salud$ entera... $[\ldots]^{22}$.

La diferencia más explícita está en la curación, que en el caso de la posesión toma la forma de una salida violenta del diablo invasor, y en la locura la de un amansamiento paulatino del furioso. Se perfila así una reordenación más extensa de las categorías que hacen referencia a los peligros del alma.

Boissier de Sauvages, en $1763^{23}$, incluye la «demonomanía», dentro de su taxonomía de las enfermedades mentales, en el mismo apartado - «delirio»- que la manía y la melancolía. Mas esa atribución procedía de una

22 Ibid., milagro 123.

23 Apud. Michel Foucault, Histoire de la Folie à l'Age Classique (Paris: Gallimard, 1972), p. 211. 
vieja discusión, viva en la primera mitad del siglo XVII, sobre la posibilidad de considerar la posesión diabólica como una forma de melancolía. Las corrientes escépticas dentro del catolicismo - como puede verse en las opiniones de Pedro de Valencia o del inquisidor Salazar y Frías respecto de las brujas ${ }^{24}$ - tendían a atribuir buena parte de los fenómenos diabólicos a desarreglos mentales o fisiológicos, y debían así sentirse atraídas por la psicopatología de la época. El mismo léxico que vemos utilizado imprecisamente en las narraciones de milagros - pasión, furioso, manía, insomnio, melancolía - es el que ya se usa en 1609 en la clasificación "científica» de Plater ${ }^{25}$. Su uso muestra, sin embargo, algunas peculiaridades dignas de atención: los fenómenos antiguamente circunscritos dentro de la "posesión» (furia, alboroto, suciedad, malos modos) son en general puestos bajo la jurisdicción de vocablos técnicos (locura furiosa, manía) y relegados al campo de la enfermedad. Por el contrario, el espacio que se suponía propio de la melancolía - compuesto por delirios o malestares interiores- es considerado como obra directa del demonio, y por ello permanece dentro del ámbito sagrado. La Iglesia comienza a interesarse prioritariamente por la vida interior del fiel, un espacio labrado y sembrado por el diablo.

Sería erróneo, sin embargo, confundir esta actitud con una especie de paleo-psiquiatría. Lo que aparece en los milagros es una teoría completa sobre el alma que tiene sentido dentro de un cuadro simbólico tradicional. A este respecto, es importante reparar en otra posible aventura del alma: la muerte y resurrección. En Valvanera los casos de resurrección son llamativamente numerosos ${ }^{26}$. El concepto de muerte que manejan es relativamente flexible. Así, en uno de los casos compendiados en el milagro 42, Jorge Martínez, durante una romería a Valvanera, cae de su montura, dándose «un golpe tan terrible, que con él despidió el alma». Sus compañeros lo encuentran «sin sentido, y sin pulso, ni la menor señal de vida». Intentan averiguar «si era desmayo, o suspensión de sentidos, o muerte, y siempre se desengañaron, que estaba muerto». No obstante, lo llevan a Tobía, donde hacen «remedios fuertes, y medicinas las más violentas, para ver si era factible dar vida al pobre cadáver». Como nada da resultado, deciden enterrarlo al menos en el santuario, y cuando se paran a rezar en el camino ya a la vista de éste el cadáver resucita. Entre la vida y la muerte no hay una frontera, sino un camino continuo por el que el alma

24 Cf. J. Caro Baroja, Las brujas y su mundo y Gustav Henningssen, El abogado de las brujas (Madrid: Alianza U., 1983).

25 M. Foucault, op. cit., p. 209.

26 La lista de Silva y Pacheco incluye 25 casos, la mayoría de los cuales está concentrada entre los números 40 y 55 . 
puede alejarse. Muerte y desmayo son por eso estados muy semejantes. En el milagro 52 (datado en 1657) el hijo de un militar sufre un "accidente a modo de desmayo, que le puso en la misma semejança de la muerte, y al parecer de todos estaba difunto». Sus padres ruegan por él a la Virgen de Valvanera, y al acabar la oración «volvió el niño del desmayo, o recuperó la vida, que se juzgó tan perdida. Preguntáronle los padres ¿Quién te dió vida, hijo? Respondió: Valvanera me vivió [...]».

En algunos casos la muerte aparece como un auténtico viaje del alma. En el milagro 47 (datado en 1617), Catalina de Gimileo pierde a su hijo Francisco. El cura se niega a darle la extremaunción por considerarle ya muerto. Después de velar toda la noche al muerto, llamándolo a voces e invocando a la Virgen de Valvanera, aquél responde: «Válgame la Virgen de Valvanera». La madre entonces le pregunta: «¿De dónde vienes, Francisco? ¿Dónde has estado estos días?» Y el hijo le responde: «Madre, estos días estuve en Valvanera: todo el tiempo que apartó del cuerpo el alma, y daré todas las señas del camino y santuario [...]»

Vale la pena reparar en la genealogía de este milagro, que ofrece un claro paralelo con el milagro de Garci Ezquier, el tercero de la lista, que Silva sitúa en el año 1426 y que por su parte parece una límpida escenificación de un milagro berceano. Garci Ezquier, vecino de Alfaro -cerca de Calahorra - se presentó en el santuario en compañía de familiares, ofreciendo a la Virgen numerosos presentes, entre ellos su propia mortaja. Este Garci Ezquier, gravemente enfermo, había sido desahuciado por los médicos y se hallaba pronto a morir. En lo más agudo de su agonía, su esposa lo encomendó en un grito a la Virgen de Valvanera, tras lo que el enfermo expiró. El cadáver fue preparado para el entierro, mas cuando comenzaba la traslación empezó a moverse y a dar voces, diciendo, entre otras cosas: «Jesús, qué terribles pasos, qué caminos tan horribles, qué sendas tan bravas tiene la Virgen de Valvanera». Los circunstantes, viéndolo resucitado, le preguntan qué ocurrió en todo ese tiempo en que su cuerpo estuvo frío. Él responde que cuando su alma se separó del cuerpo, se armó pleito entre un Ángel y un Demonio que quería impedir al alma que subiera al santuario de Valvanera. Venció el ángel, que le condujo hasta el lugar sagrado; pero llegado hasta la cruz del camino de donde éste se divisa, se le interpuso un fantasma, o monstruo infernal. La Virgen María apareció entonces, enviando el diablo a los infiernos, y el Ángel pudo acompañar el alma hasta la imagen, que le devolvió la vida, haciendo que el ángel la llevase de vuelta a su casa y a su cuerpo. Garci Ezquier, que nunca había peregrinado a Valvanera, pudo dar cuenta a algunos vecinos que sí lo habían hecho de los detalles del camino, describiendo cruces, sendas, campos, montes, los altares de la iglesia y las lámparas encendidas ante la imagen. Recobrada 
la salud hizo, esta vez a pie, la romería a Valvanera, ese recorrido que describimos al inicio de este trabajo, desde el valle hasta la sierra.

\section{EL DIABLO Y LA INGENIERÍA SIMBÓlICA}

Para entender su aventura, debemos también rehacer ese camino.

El diablo tiene historia, una historia que en España empieza con la expansión del cristianismo. La conversión y la catequización no se logran tanto por un culto positivo - por la instauración de nuevos personajes sagradoscuanto por la definición de un enemigo, al principio humilde y disperso, después personal y poderoso. Sólo en parte ese enemigo es tomado de la demonología clásica; en la medida en que el cristianismo y su demonio germinan, éste desarrolla un carácter y sobre todo una altura nuevos.

Las primeras apariciones del diablo - esos «diablos latinos»- obedecen a una lógica bastante simple de inclusión y exclusión. Fuera del cristianismo sólo puede existir, a lo sumo, hechicería. La sociedad señorial tardorromana, rígida y estable, aparece en los textos de Prudencio como una isla -urbana- rodeada por una «gentilidad» potencialmente hostil. El diablo es un extranjero, introducido en el cuerpo y que martiriza el cuerpo. El santo, o mejor el mismo centro consagrado en que reposan sus reliquias, lo expulsa. El diablo es un extranjero también porque habita la "gehenna», es decir, un topos bíblico sin referencia en la cultura local.

En el San Millán latino esa lógica de inclusión y exclusión se conserva básicamente igual, pero con las complicaciones dadas por la extensión de la «isla» cristiana. Ya no hay una ciudad concreta, cuyas murallas señalen los límites entre fieles y gentiles. Son las andanzas del santo exorcista - extraído, como vimos, de la periferia del cristianismo- las que definen esos límites.

El panorama varía un poco si en lugar de ese punto de vista global del cristianismo usamos el de la comunidad rústica que adopta el culto del santo. En ella el santo tiene algo de hechicero y contra-hechicero. El poder del santo gana en esa escala un valor de eje del universo; el santo es capaz de expulsar los demonios que invaden su dominio, pero es el único capaz también de encontrarse con el diablo en persona, invadir a su vez su territorio y derrotarlo. Es decir, en el santo el exorcismo y el viaje «shamánico» (por usar una expresión muy popular en la tradición antropológica) se muestran como caras de la misma moneda, tal como Lewis postula para culturas muy lejanas del cristianismo ${ }^{27}$. El poder del santo no carece por

27 I. M. LEWIS, op. cit. 
ello de una cierta ambigüedad, como el del shamán: habitualmente cura, pero es capaz también de hacer daño (como hace en la Vita con dos ladrones que le roban una montura, a los que ciega con sus oraciones). En su figura se ordena un universo religioso completo, que tiene sentido dentro de los límites de una comunidad concreta $-\mathrm{y}$ es así lo contrario de lo que pretende una Iglesia con ímpetus universalistas.

Ahora bien, ese espacio «otro» contenido por la acción del santo es imaginado de modos divergentes. En la versión del «rústico», la separación parece establecerse entre comunidad y naturaleza, y el diablo - varias veces calificado como habitante de los yermos- no pasa de ser una de las manifestaciones de esa dicotomía, como el mismo yermo inquietante, o como las serpientes que lo habitan. La lógica que la «intelectualidad» cristiana establece es algo muy diferente: el espacio del diablo es diseñado como un espejo que invierte la sociedad cristiana, y más especialmente la sociedad eclesiástica, propuesta como su modelo. La naturaleza no es para el cristianismo algo sustantivo, un «otro» lo bastante digno como para medirse con él. La naturaleza -en rigor un caos de elementos naturales- sirve únicamente para expresar la indefinición del diablo, sus omnímodos poderes de manifestación. En otras palabras, encontramos en los textos de Berceo - con tanta razón considerado un nexo entre «cultura popular» y «cultura erudita»- un punto de vista, el rústico, según el cual el diablo es un epifenómeno de la naturaleza, y otro, el culto, según el cual la animalidad suele ser un epifenómeno de lo diabólico.

Las consecuencias de este matiz son amplias, y ya se perciben en la obra del mismo Berceo. El cristianismo no elabora su teología sobre la complejidad de relaciones entre seres diferentes que la naturaleza sugiere ${ }^{28}$; limita su universo simbólico a la vida humanizada e introduce en ésta una única y radical diferencia entre lo bueno y lo malo. Se inventa una sociedad diabólica que invierte el modelo de la sociedad cristiana y consecuentemente se diabolizan los grupos humanos marginales a ésta. Se concede un lugar al akelarre o a la obsesión antijudáica.

Pero no es ése el único desarrollo del diablo. Hay otro, más complejo, que lo liga a una «otredad» tan compleja como la de él mismo: la femenina. Una vez establecido que hay un universo diabólico que invierte los valores del cristiano, la mujer - la Virgen María- se constituye en principal mediadora entre ambos. La Virgen, por así decirlo, reintroduce en el cristianismo la ambigüedad que había sido excluida con la naturaleza; y la mediación entre lo moral y lo inmoral no puede ser sino una función

28 La idea de que la naturaleza sea una fuente de variedad, o de acervos clasificatorios, está tomada del clásico de Claude Levi-Strauss, La Pensée Sauvage. 
amoral. El vínculo de devoción que se establece entre el fiel y la Virgen prevalece sobre cualquier frontera establecida entre el bien y el mal, y es contemporáneo del crecimiento del poder real por encima de las ciudades, de las comunidades y de los señores en la Baja Edad Media. Poco significan en esa nueva situación los santos locales. Ya no hay sólo un poder (santo) interno y un antipoder (diabólico) externo; la Virgen es un poder santo pero externo. En ese trípode puede apoyarse entonces una experiencia religiosa individual que antes se disolvía en el holismo de la comunidad o su apostasía; la arbitrariedad del poder de la Virgen posibilita aventuras personales, y el trato dudoso con el diablo.

La Baja Edad Media es un período en que estas versiones del diablo florecen y conviven; a partir de ahí, sin embargo, comenzará a crecer alguna distancia entre ellas. El motivo será el control del alma humana.

A partir de la próspera mitología del diablo que ha sido expuesta aquí, habíase creado toda una teoría del alma, en que se preveían una serie de situaciones típicas que han sido sucesivamente presentadas. Un estado de «salud» en que el alma rige el cuerpo $(+)$ y el diablo se mantiene apartado $(-)$; un estado de "posesión» en que el demonio penetra en el cuerpo ( + ) y se sobrepone al alma (-); una "perturbación» en que el diablo se aproxima $(+)$ al cuerpo, influyendo en el curso del alma $(+)$; y por fin el akelarre o sabbath, en que el alma abandona el cuerpo (-) y se une al clan diabólico en una fiesta que tiene lugar fuera de los límites (- ${ }^{29}$.

Por ricos que puedan ser los matices de este abanico, es fácil reducirlo a un sistema simple de inclusiones y exclusiones, o de presencias y ausencias:

$$
\begin{aligned}
& \text { alma }+ \text { diablo }-\ldots \ldots \ldots \ldots \ldots \ldots \ldots \ldots . .+ \text { alma }+ \text { diablo } \\
& \text { salud perturbación } \\
& \text { akelarre posesión } \\
& \text { alma }- \text { diablo }-\ldots \ldots \ldots \ldots \ldots \ldots \ldots . \text { alma }+ \text { diablo }
\end{aligned}
$$

Todas esas modalidades tienen una presencia viva en el léxico castellano. En la posesión «se tienen los demonios en el cuerpo» o se está «fuera de sí»; en la perturbación el diablo «te tienta» y al akelarre se va cuando a uno «se lo llevan los demonios». De todas esas circunstancias peligrosas se está a salvo por fin cuando «se vuelve en sí».

29 En los procesos de brujería a veces se alega que el acusado de asistir al akelarre había sido visto por un cónyuge durmiendo en la noche de autos; ese argumento es desechado, porque era su espíritu el que había viajado, o bien porque el diablo había dejado en su lugar un simulacro, etc. 
Este juego pone un cuadro completo de conceptualización de las enfermedades y su cura, y un repertorio completo de ese universo religioso que antes llamábamos «chamánico» en manos de la población iletrada. Con el trato diabólico, un común mortal puede hacer lo que hacían los viejos santos, y eso en el universo entero, y no en una comunidad estrecha. La Iglesia favoreció la popularización de ese esquema porque, como se vio, la expansión de sus figuras sagradas no era posible sin el concurso de un antagonista; el carácter unilateral de la divinidad cristiana, identificada sólo con el Bien, la había hecho dependiente de su enemigo. El arte medieval, en todas sus manifestaciones, postuló la omnipresencia del diablo y acabó así expresando un cristianismo diabolizado en que las divinidades no pasan de ser trasuntos de su Contrario. Pensadores ingleses del siglo XVII, como muestra Keith Thomas ${ }^{30}$, consideraban que la existencia del diablo - tangible en numerosas posesiones, visiones, etc.- era la prueba máxima de la existencia de Dios. Esa situación era en definitiva indeseable para la Iglesia, representante de Dios y de algún modo excluida por el crecimiento de lo excluido, y llevada por su propia predicación a actuar meramente como represora ${ }^{31}$. Caso extremo y bien estudiado es el de las «epidemias de brujería» de comienzo del siglo XVII, en cuya difusión fueron tan decisivas las vigorosas y funestas predicaciones de los edictos de gracia inquisitoriales ${ }^{32}$. La actitud de los inquisidores a partir de entonces tendió a controlar tales excesos y a devaluar ese universo diabólico de consecuencias tan imprevisibles.

No es gratuito que en siglo XVII el léxico psicológico se enriquezca y el diablo se naturalice. Convertir los disturbios del alma en enfermedad mental es lo mismo que sustituir la relación horizontal del alma y su contrincante el diablo por la relación jerárquica entre el fiel carente (alma y cuerpo bien atados) y la divinidad sobrenatural y poderosa. Esta nueva «teoría del alma» se construye con una sola variable, y por eso sus polos son más momentos de un continuum que variantes combinatorias:

\begin{tabular}{|c|c|c|c|}
\hline $\begin{array}{l}\text { exceso } \\
\text { (manía, locu- } \\
\text { ra furiosa) }\end{array}$ & $\begin{array}{l}\text { - equilibrio } \\
\text { (presencia } \\
\text { de ánimo) }\end{array}$ & - & $\begin{array}{c}\text { escasez } \\
\text { (melancolía) }\end{array}$ \\
\hline
\end{tabular}

30 Religion and the Decline of Magic (Widenfold \& Nicholson, 1980), p. 476.

31 Los estudios de religión que utilizan categorías como «hegemónico» y «subalterno» tienden a enfatizar en exceso el carácter represor de ese primer polo; intento sugerir aquí que la adopción de políticas simbólicas «positivas», como la creación y difusión de cultos, tienen un papel mucho más decisivo para esa hegemonía.

32 G. HENNINGSSEN, op. cit. 
La aflicción se había definido como producto de la tensión entre un núcleo interior y un agente externo. Por eso la peregrinación que sumerge al sujeto en un ámbito «otro», puede sustituir la lucha con el demonio. No se trata de extirpar algo ajeno, sino de restaurar la intensidad media del alma haciéndola recorrer un circuito cuyos extremos tienen signos diferentes. Gracias a la romería - en el camino del hogar a un santuario selvático y lejano ${ }^{33}$ - los endemoniados se calman, los melancólicos se animan y los difuntos vuelven. El diablo interviene infructuosamente para cerrar el paso, para aislar los diversos estados. La Virgen, actualizando en las visiones de los fieles los viejos ejemplos de la literatura medieval, lo derrota garantizando la comunicación, sacando al simbolismo cristiano de dualidades de corto alcance. La Virgen es el mayor triunfo del cristianismo en España. No, como suele decirse, porque sirva como intercesora ante una divinidad paterna y severa; como hemos dicho, el silencio que la documentación guarda sobre el Dios bíblico y el mismo Cristo relativizan su relevancia. La Virgen impera como figura sagrada porque, cifrada en su contradictoria sexualidad (concebida sin pecado, virgen y madre) recupera una ambigüedad de lo sagrado perdida por la cisión de Dios y Diablo ${ }^{34}$.

Un examen del arte y la literatura del barroco podría, tal vez, darnos una idea de cómo la educación del alma individual se liga desde entonces más estrechamente a esta figura, sustituyendo en parte la psicomaquia por una afectividad melíflua y absorbente. Apagadas las minorías religiosas españolas y pasadas a segundo plano las luchas con turcos o protestantes, el diablo fue perdiendo también la fuerza que obtenía de ser metáfora de unos y otros. En el siglo XVII los dos últimos reyes Austrias, Felipe IV y sobre todo Carlos II, fueron muy acosados o poseídos por demonios. En el XVIII los dos primeros Borbones, Felipe $\mathrm{V}$ y Luis I, no estaban tampoco muy en sus trece, pero ya nadie habló de posesiones. El imperio diabólico había perdido mucho territorio, y el diablo comenzaba una nueva y próspera carrera en otros pagos y con otro estilo.

\section{ÓsCar CALAVia Sáez}

Universidad de São Paulo, Brasil

33 Interesa observar el carácter negativo que - por ejemplo en el milagro de Garci Ezquier - se atribuye al paisaje de Valvanera.

34 Desarrollo este tema en otro artículo: O. CALAviA, «Sobre la mujer simbólica», L. DIAz (ed.), Aproximación antropológica a Castilla y León (Barcelona: Anthropos, 1988), pp. 219-258. 
Este trabajo intenta trazar la historia del diablo desde el inicio del cristianismo hasta el siglo XVII en una región delimitada, correspondiente más o menos a la actual provincia de La Rioja. Sustitúyese cualquier concepto previo de «diablo» por las representaciones concretas que pueden reconocerse en los documentos. En lugar de una figura estable, heredera de tradiciones pre-romanas o pre-cristianas, se revela así un personaje que evoluciona de un simple espíritu invasor a rey infernal o perturbador del alma. Las figuras de más peso del panteón católico - la Virgen y los santos - se elaboran y difunden a su sombra. El diablo ocupa por un buen tiempo el centro efectivo de la doctrina cristiana, y juega un gran papel en la creación del espacio psicológico interior.

This paper tells the history of the Devil from the beginning of Christianity to the 17th century, using documents linked to a restricted region in the north of Spain. The purpose is to recognize concrete figures of the Devil in a certain space and time instead of enforcing previous conceptions about him. Far from being a stable figure, adapted from pre-christian or classical lore, the Devil evolues in this long-time range. He goes from a intruder spirit, through semi-animal qualities, to a higher or/and subtler form as King of a realm of his own, or as soul disturber. The Devil, thoroughly popularized, is the major core in the making and diffusion of the Catholic pantheon personages such as the Saints, and the Holy Virgin. He seizes for a time the real center of Christian effective theology. The Devil appears also as the creator of soul interior experience in Christian culture. 